\title{
XIV. A calorimetric determination of energy dissipated in condensers
}

\section{Edward B. Rosa \& Arthur W. Smith}

To cite this article: Edward B. Rosa \& Arthur W. Smith (1899) XIV. A calorimetric determination of energy dissipated in condensers, Philosophical Magazine Series 5, 47:285, 222-236, DOI: 10.1080/14786449908621252

To link to this article: http://dx.doi.org/10.1080/14786449908621252

曲 Published online: 08 May 2009.

Submit your article to this journal $[\pi$

Џ Article views: 2

Q View related articles $\asymp$ 
sible that the resistance might not tend to vanish, but, as in the case apparently of bismuth, might increase with further fall of temperature. It has been suggested that at very low temperatures all metals might become magnetic. It is very probable that the change of electrical structure here indicated would be accompanied by remarkable changes in the magnetic properties. These are some of the points which experiment will probably decide in the near future. The only experimental verification at present available is the observation of Dewar in the case of platinum No. 3 when immersed in boiling hydrogen at $-240^{\circ} \mathrm{C}$, that the resistance after attaining a very low value apparently refused to diminish further, in spite of a considerable lowering of the pressure. It would be extremely interesting to repeat this observation with specially constructed thermometers of copper or iron, which ought to show the effect in a more striking manner and at a higher temperature.

My thanks are due to Messrs. E. H. Griffiths, C. T. Heycock, and F. H. Neville, and to Prof. A. W. Porter and Mr. N. Eumorfopoulos, for their kind assistance in revising and correcting the proofs of this article.

XIV. A Calorimetric Determination of Energy Dissipated in Condensers. By Edward B. Rosa and Arthur W. Smith*.

I $\mathrm{N}$ a former paper (suprà, p. 19) we gave the results of mea1 surements by means of a wattmeter of the energy dissipated in condensers when they were subjected to an alternating electromotive force. The results were such that we desired to confirm them by a totally independent method: and, in addition, to measure the energy dissipated in some paraffinedpaper condensers which showed so small a loss that with the coils at our disposal the Resonance Method, employed successfully on beeswax and rosin condensers, would not give sufficiently accurate values. We therefore constructed a special calorimeter for the purpose of measuring the total quantity of heat produced in the condensers, which represents the total energy dissipated.

Fig. 1 gives an external view of the calorimeter, and fig. 2 a vertical section. The calorimeter proper, $A$, is the inner of three concentric boxes, and is $33 \mathrm{~cm}$. long, $30 \mathrm{~cm}$. deep, and $10 \mathrm{~cm}$. in breadth. It has a copper lining, $a$, and a copper jacket, $b$, and is protected by the two exterior boxes from fluctuations of temperature without. The general principle of the calorimeter is (1) to prevent any loss or gain of heat

* Communicated by the Authors. 
through its walls, and (2) to carry away and measure all heat generated within by a stream of water To effect the first condition two concentric copper walls (the lining and the jacket) are maintained as nearly as possible at the same temperature. This, of course, will reduce the flow of heat through the intervening wooden wall to a minimum, and make the "cooling correction" small, if not zero.

Fig. 1.

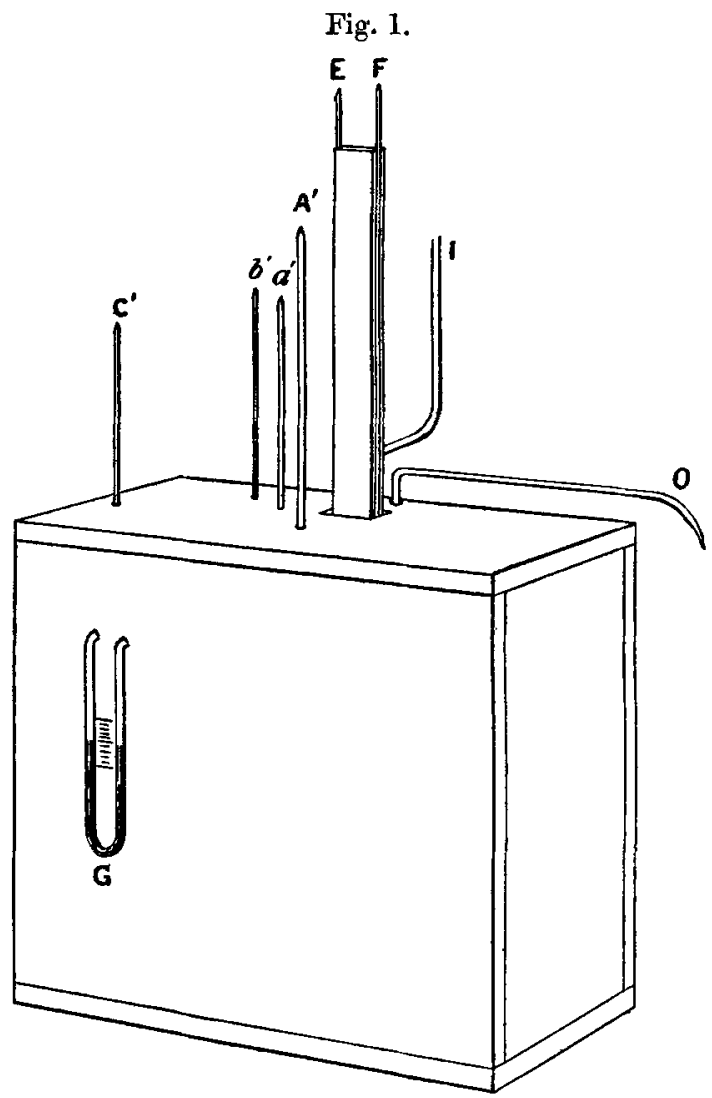

\section{To Eliminate the Cooling and Capacity Corrections.}

In order to ascertain any difference of temperature between the copper walls $a$ and $b$, a differential air-thermometer is used. Each air-chamber of this differential thermometer consists of a copper pipe about 4 motres long and 4 millim. internal diameter, one coiled about and soldered to the lining, 
and the other coiled about and soldered to the jacket. One end of each pipe is closed and the other connected to one end of the U-tube, $\mathrm{G}$, shown on the outside of the calorimeter in fig. 1. The U-tube, which we call the gauge, contains kerosene oil, and serves to indicate any difference of temperature between the two copper walls. The zero-mark is fixed after

Fig. 2.

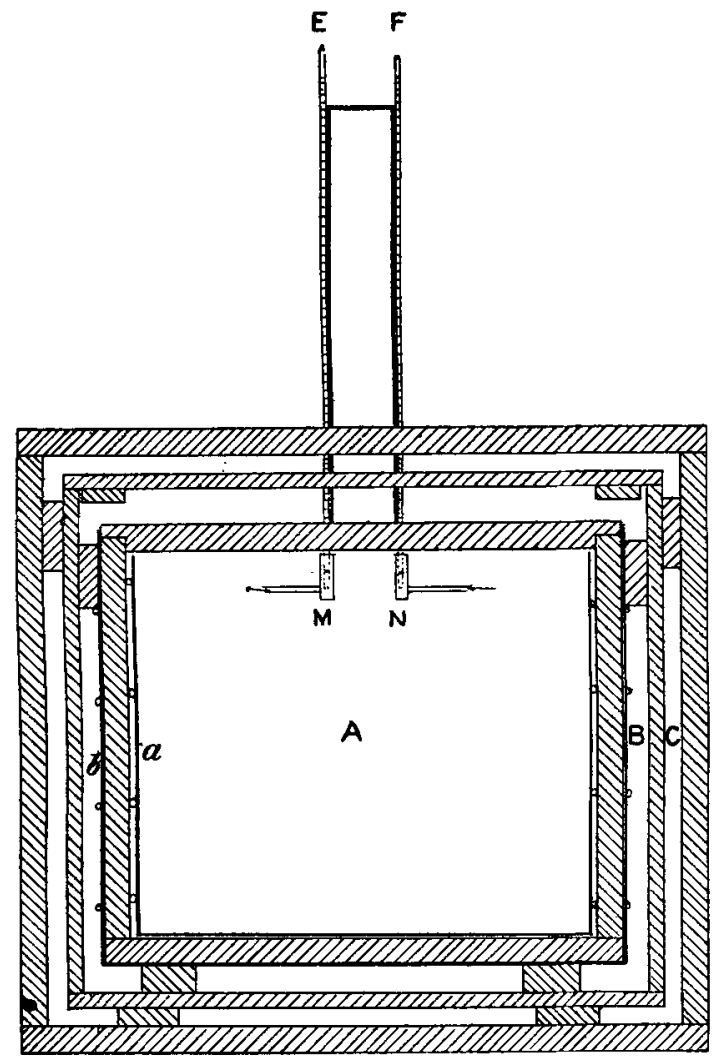

maintaining the whole calorimeter at a constant temperature for some bours. In order to keep the gauge reading sensibly zero, and thus keep the two copper walls very closely at the same temperature, a coil of wire through which an electric current of any desired strength can be passed is wound about the jacket in the space B. And in order to make the regulation more perfect a second coil is wound about the second box in 
the space $\mathrm{C}$, so as to maintain the temperature of this space nearly constant. The temperature of the chamber $A$ is usually kept a little higher than the external temperature, so that no cooling is required; and by varying the currents in the two heating-coils the temperature in $\mathrm{B}$ can be made to follow that in $A$ so closely that the gauge-readings are always small, and their algebraic sum during any experiment zero. This eliminates all correction for radiation. In rare cases when the temperature of the room has risen considerably, we have found it necessary to hang a wet cloth about the box to prevent the temperature of $\mathrm{C}$ rising above that of $\mathrm{B}$ and $\mathrm{A}$. We intend to coil a small copper pipe in C so that a stream of cool water may be sent through it, and then no difficulty will be encountered in the hottest weather.

In addition to the gauge four thermometers (fig. 1) indicate the temperatures of $A, a, b$, and $\mathrm{C}$ : that is, $\mathrm{A}^{\prime}$ shows the temperature of the air in the calorimeter chamber $A$; $a^{\prime}$ has its bulb in a pocket of the lining $a$, and hence indicates the temperature of the wall $a ; b^{\prime}$ similarly extends down into a pocket of the copper jacket $b$, and shows its temperature. Finally, $\mathrm{C}^{\prime}$ gives the temperature of the outer air-space $\mathrm{C}$. $\mathrm{A}^{\prime}$ is an accurate thermometer reading from $20^{\circ}$ to $25^{\circ} \mathrm{C}$., graduated to $0^{\circ} .01$ and read to $0^{\circ} .001 \mathrm{C}$. If $A^{\prime}$ shows the temperature to be constant during the whole period of an experiment, or the same for a considerable time near the end of an experiment that it was at the beginning, then there will be no correction for heat absorbed or given up by the apparatus. With both the "cooling correction" and the capacity correction eliminated, it remains to carry away and measure the entire heat generated by a condenser in A, or by any other source of heat within the calorimeter.

\section{Carrying away and Measuring the Heat.}

In order to carry away the heat generated a stream of water, which enters at I (figs. 1 and 3 ), is made to flow through a coiled copper pipe (fig. 3), where it absorbs heat, and then leaves the calorimeter at $O$. In order to increase its absorbing capacity the pipe is soldered to a sheet of copper, I. L, both pipe and copper being painted black. Three such sheets, each with 4 metres of pipe attached, are joined together and placed side by side in the chamber $\mathrm{A}$, the condensers being slipped in between them. The rate of absorption of heat depends upon the difference of temperature between the absorbers and the air surrounding them. If a large 
amount of heat is to be brought away, the water is made to enter at a low temperature and to flow rapidly through the absorbers. If a smaller quantity of heat is to be absorbed and carried away, the entering water will be warmer, and its gain in temperature correspondingly less. By varying the temperature of the water and its rate of flow, the rate of absorption can be varied between wide limits, and kept very

\section{Fig. 3.}

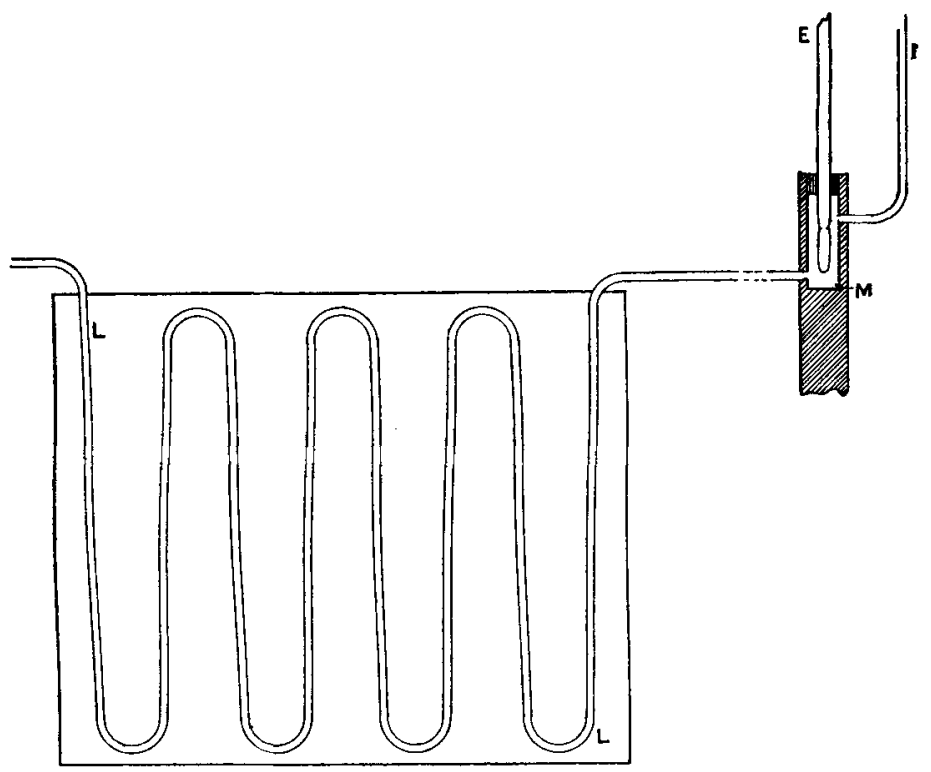

nicely at any desired point. In practice the thermometer $\mathrm{A}^{\prime}$ is the guide in regulating the temperature of the entering water. If the temperature of $A$ begins to rise ( $A^{\prime}$, as already stated, can be read to one-thousandth of a degree), the entering water is slightly cooled; if to fall, it is slightly warmed; the rate of flow of water, after being once adjusted for a given experiment, is maintained constant.

In order to measure the quantity of heat thus carried away, the thermometers $\mathrm{E}$ and $\mathrm{F}$ are inserted in two small reservoirs, $\mathrm{M}$ and $\mathrm{N}$, which stand in the wooden wall of the calorimeter between the two copper surfaces. The thermometer $\mathrm{E}$ indicates the temperature of the water just as it enters the chamber $A$, and the thermometer $F$ gives its temperature as it leaves. The difference of temperature multiplied 
by the mass of water per second gives the rate of absorption and removal of heat. The thermometers are accurately graduated and read to hundredths of a degree. The gain in temperature is several degrees, and may be ten or twenty degrees by increasing the quantity of heat generated or reducing the rate of flow of water. Hence the accuracy of the determination of the quantity of heat absorbed is sufficient for most purposes. The chief error is ordinarily due to changes in the temperature of the apparatus itself and its contents. By running the experiment several hours, however, and keeping it as nearly as possible at a constant temperature, this uncertainty is greatly reduced and the error made negligibly small.

The water flows into the calorimeter from a reservoir about a metre above, this height furnishing the necessary pressure. The temperature of the entering water is regulated by adding warm or cold water to the reservoir, and the rate of flow of the water is regulated by an adjustable valve. The water is collected in a litre flask, the time of each litre being recorded.

\section{Test of the Calorimeter.}

Table I. shows the result of one of the tests made upon the calorimeter. A current of electricity passed through a coil of wire within the chamber $A$, the electromotive force being measured by a carefully calibrated Weston voltmeter, and the current by a Kelvin balance. The experiment continued for a little more than four hours, while nine litres of water passed through the caiorimeter. The rate of absorption of heat was nearly, but not quite, constant, the temperature as indicated by $\mathrm{A}^{\prime}$ having varied slightly. The final temperature was practically the same as that at the beginning, being slightly higher if anything. The average for the nine litres is 12.37 watts absorbed and carried away by the water, while the electrical measurements give 12.34 watts. By continuing the experiment longer and introducing greater refinements in the measurement of the current and electromotive force, a greater degree of accuracy could undoubtedly be attained. But this and other tests showed clearly that for our present purposes the calorimeter was abundantly accurate, and we proceeded to put some condensers into it and measure the heat evolved. 
TABLE I.

Test of the Calorimeter.

\begin{tabular}{|c|c|c|c|c|c|c|c|}
\hline Time. & $\begin{array}{c}(c) \\
\text { Period in } \\
\text { seconds } \\
\text { for each } \\
1000 \mathrm{grm} . \\
\text { of water. }\end{array}$ & $\begin{array}{l}(d) \\
\text { Average } \\
\text { tempera- } \\
\text { ture of } \\
\text { the } \\
\text { ingoing } \\
\text { water. }\end{array}$ & $\begin{array}{c}(e) \\
\text { Average } \\
\text { tempera- } \\
\text { ture of } \\
\text { the out- } \\
\text { ', going } \\
\text { water. }\end{array}$ & $\begin{array}{c}(f) \\
\text { Increase } \\
\text { in tempe- } \\
\text { rature of } \\
\text { each } \\
1000 \mathrm{grm} \\
\text { of water. } \\
(e)-(d)\end{array}$ & $\begin{array}{c}(g) \\
\text { Total } \\
\text { hent } \\
\text { measured } \\
\text { (small } \\
\text { calories). } \\
(f) \times 1000 .\end{array}$ & $\begin{array}{c}(h) \\
\text { Small } \\
\text { calories } \\
\text { per } \\
\text { second. } \\
(g) \div(c)\end{array}$ & $\begin{array}{c}(i) \\
\begin{array}{c}\text { Equivalent } \\
\text { watts }= \\
\text { calories } \times \mathrm{J} . \\
(h) \times 4 \cdot 1972 .\end{array}\end{array}$ \\
\hline $\begin{array}{lll}\text { h. } & \text { m. } & \text { s } \\
1 & 53 & 00 \\
2 & 19 & 45 \\
2 & 46 & 50 \\
3 & 13 & 55 \\
3 & 41 & 15 \\
4 & 09 & 10 \\
4 & 37 & 10 \\
5 & 04 & 10 \\
5 & 32 & 15 \\
6 & 01 & 00\end{array}$ & $\begin{array}{l}1605 \\
1625 \\
1625 \\
1640 \\
1675 \\
1680 \\
1620 \\
1685 \\
1725\end{array}$ & $\begin{array}{l}15 \cdot 66 \\
15.70 \\
15.74 \\
15.70 \\
15 \cdot 72 \\
1557 \\
15.64 \\
15.55 \\
15 \cdot 57\end{array}$ & $\begin{array}{l}20 \cdot 39 \\
20 \cdot 44 \\
20 \cdot 51 \\
20 \cdot 53 \\
20 \cdot 64 \\
20 \cdot 56 \\
20 \cdot 58 \\
20 \cdot 50 \\
20 \cdot 56\end{array}$ & $\begin{array}{l}4.73 \\
4.74 \\
4.77 \\
4.83 \\
4.92 \\
4.99 \\
4.94 \\
4.95 \\
4.99\end{array}$ & $\begin{array}{l}4730 \\
4740 \\
4770 \\
4830 \\
4920 \\
4990 \\
4940 \\
4950 \\
4990\end{array}$ & $\begin{array}{l}2 \cdot 947 \\
2 \cdot 917 \\
2 \cdot 935 \\
2 \cdot 945 \\
2 \cdot 937 \\
2 \cdot 970 \\
3 \cdot 050 \\
2 \cdot 950 \\
2 \cdot 893\end{array}$ & $\begin{array}{l}12 \cdot 37 \\
12 \cdot 24 \\
12 \cdot 32 \\
12 \cdot 36 \\
12 \cdot 33 \\
12 \cdot 47 \\
12 \cdot 79 \\
12 \cdot 33 \\
12 \cdot 14\end{array}$ \\
\hline & & & & & & & $12 \cdot 37$ \\
\hline
\end{tabular}

Electromotive force $=20.0$ volts.

Current $=0 \cdot 617$ ampere.

Watts (from electrical measurements) $=20 \cdot 0 \times 0 \cdot 617=12.34$.

\section{The Experiments.}

Table II. (p. 230) gives the results of six experiments with the same beeswax and rosin condensers which were employed in our work by the resonance method. In each experiment a preliminary run, not included in the table, allows the condensers and calorimeter to come to a constant temperature. Column (a) gives the numbers of the condensers in each case, they all being joined in parallel to the same electromotive force. Column $(b)$ gives the time of the beginning of each litre of water; column $(c)$ the duration of each litre or 1000 grammes of water; column (d) the average temperature of the ingoing water as found from readings of the thermometer $\mathrm{E}$, taken regularly every five minutes, and column $(e)$ the same for the outgoing water; $(f)$ then shows the increase of temperature. Column $(g)$ gives the number of calories of heat carried away by each 1000 grammes of water, and column $(h)$, which is the number in $(g)$ divided by the corresponding number of seconds recorded in $(c)$, is the rate of absorption of heat. Column (i) gives the number of watts to which this is equivalent, taking 
$J$, the mechanical equivalent of heat, to be $41,972,000$ ergs. This is the value derived from Rowland's and Griffiths's work. assuming the specific heat of water at an average temperature of $20^{\circ} \mathrm{C}$. to be unity. Column $(j)$ gives the frequency. Sometimes this was estimated from the average frequency of the dynamo supplying the lines of the Middletown lightingcircuits at the time; and in other cases it was determined by measuring the speed of a small synchronous motor. The electromotive force $(k)$ was measured with an electrometer, the current $(l)$ with a Siemens dynamometer. Column $(n)$ gives the values of $\cos \phi$ of the expression power $=E I \cos \phi$. Care was taken in every instance to avoid the presence of upper harmonics, in some cases using a resonance-coil to quench the harmonics as well as increase the voltage on the condenser. Column $(o)$ gives the per cent. loss, $100 \pi \cot \phi$, and column $(p)$ the net efficiency. This relative loss, $\pi \cot \phi$, has been proved* to be the ratio of $w$ to W, where $w$ is the energy dissipated per half-period, and $W$ is the energy stored in the condenser at each charge. $1-\pi \cot \phi$, the net efficiency, is theretore

$$
\frac{\text { Energy stored - Energy lost. }}{\text { Energy stored }}
$$

\section{Beeswax and Rosin Condensers.}

The first experiment, with condensors Nos. 3, 4, and 7, showed a net efficiency of 93.39 per cent., or a loss of 6.61 per cent. The temperature of the condensers was not determined; but from the fact that the dielectric was softened and the quantity of heat generated was more than in any succeeding experiment, we feel sure that it was considerably above $40^{\circ} \mathrm{C}$. Six condensers were then placed in the calorimeter, joined in three pairs. Nos. 1 and 5 gave no sound when joined to an alternating E.M.F. of 1000 or more volts, and we called it the " best pair." In Nos. 3 and 4 vibrations were distinctly felt when the fingers were placed in contact with them, while the condensers gave a clear musical note and on the higher voltages a hissing sound; this wo called the "poorest pair." Nos. 8 and 9 were intermediate.

These six condensers were first of all joined in parallel and connected to a low-frequency eircuit of 1520 volts and 26 periods per second. Care was taken to exclude upper harmonics. The experiment continued over three hours after the temperature of calorimeter and condensers had become

* See our paper, Phil. Mag. Jan. 1893.

Phil. Mag. S. 5. Vol. 47. No. 285. Feb. 1899. 
TABLE II.-Measurements of Energy dissipated

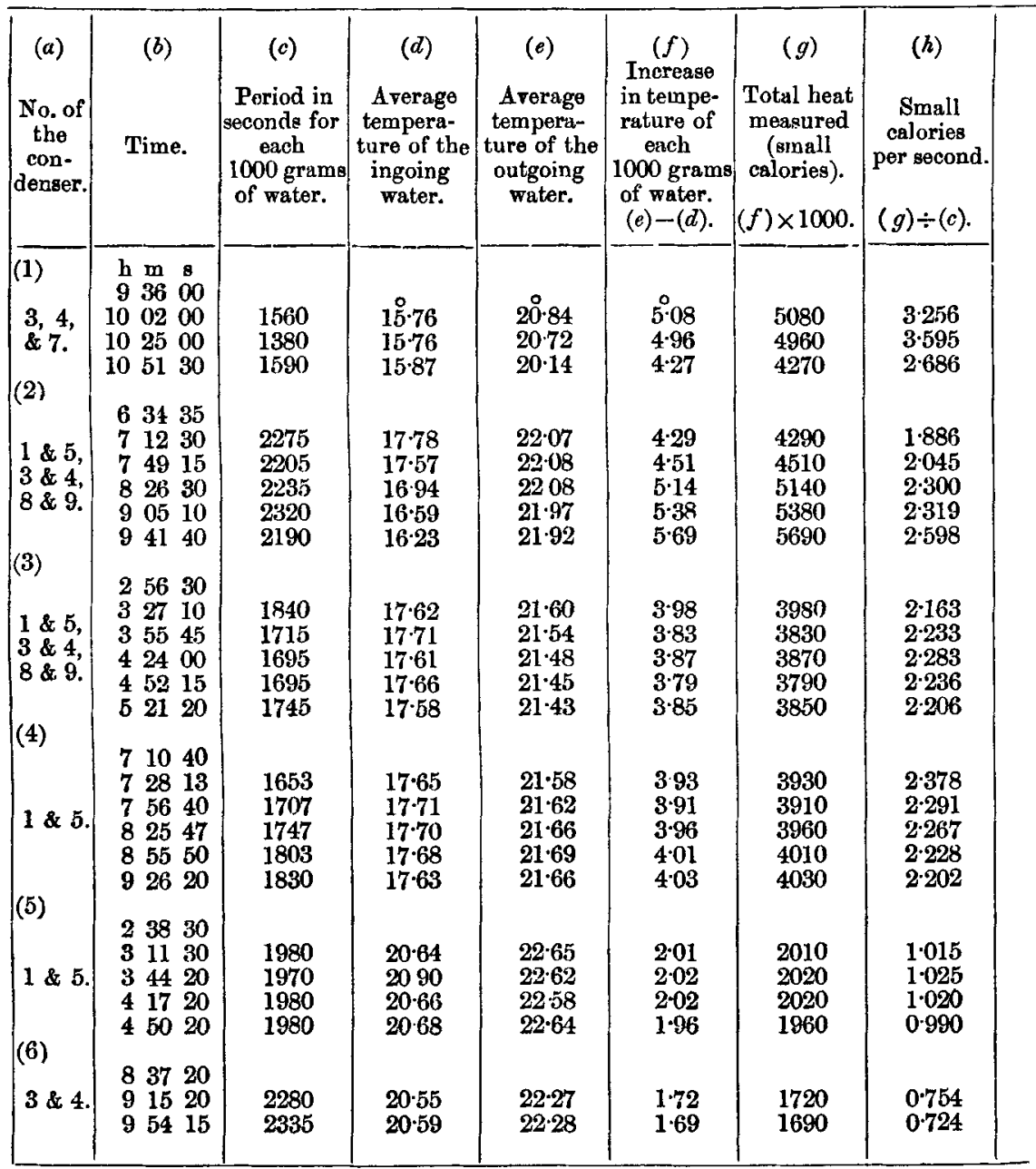


Determination of Energy Dissipated in Condensers. $\quad 231$

in Beeswax and Rosin Condensers.

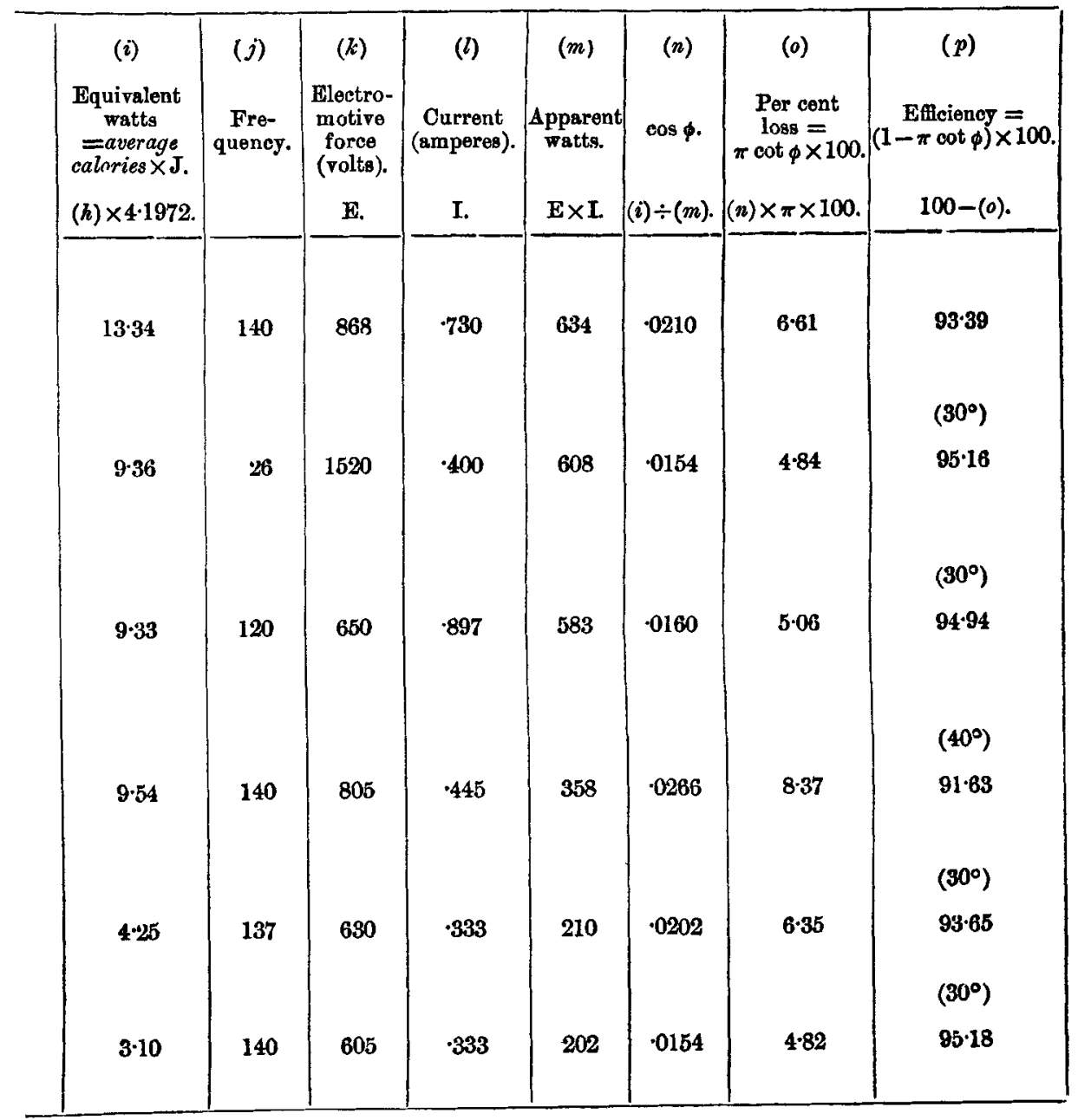

R 2 
constant by a preliminary run of several hours. The temperature of the calorimeter as indicated by the thermometer $\mathrm{A}^{\prime}$ rose gradually for an hour, and hence the heat absorbed was less than the average. During the last hour the temperature was reduced by quickening the rate of flow and cooling the entering water, so that the temperature was substantially the same at the end as at the beginning. The per cent. of loss is 4.84 at an average temperature of the condensers of $30^{\circ} \mathrm{C}$. The voltage employed on this low-frequency test was much higher than for any other experiment, and yet there was no evidence of brush-discharge or appreciable leakagecurrent.

In the third experiment the same condensers were subjected to a high-frequency electromotive force at $30^{\circ} \mathrm{C}$., and the loss found to be 5.06 per cent., that is, slightly greater than before. Hence for a given voltage the energy dissipated per period would be slightly greater, and the energy dissipated per second more than five times as much as for the low frequency.

In the fourth experiment only the "best pair" of condensers was used, and with a slightly higher voltage the temperature of the condensers rose to $40^{\circ} \mathrm{C}$. Here the loss was found to be 8.37 per cent., nearly as much as the maximum value found by the resonance method.

The fifth experiment, with the "best pair," was made gome days later at $30^{\circ} \mathrm{C}$., and the percentage loss came out 6.35 per cent., that is greater than the average of the six. This was unexpected, as well as the last result, which showed a loss for condensers 3 and 4 , the "poorest pair," of 4.82 per cent., which was less than the average. These results were then confirmed by an independent method, showing conclusively that the so-called "poorest pair" had the smallest loss; not, of course, because it emitted a distinet sound and hissed on high voltages, but in spite of that. The chief loss is doubtless due to some cause quite independent of the singing and hissing, and happens to be smaller where it would naturally be expected to be larger.

Thus we have confirmed by these calorimetric measurements the large values of the losses which we found by the resonance method in beeswax and rosin condensers, and also the existence of a well-marked maximum as the temperature rises, beyond which the loss decreases considerably. It is an interesting fact that the residual charges of these condensers are very large, that they increase with the temperature up to $40^{\circ} \mathrm{C}$., and then decrease as the temperature is carried higher. That is, the maximum point for the residual charge is the same as for the energy loss. 


\section{Paraffined-Paper Condensers.}

The second lot of condensers used were commercial paraffinedpaper condensers made by the Stanley Electric Co. A finished condenser is a solid slab about $25 \times 30 \mathrm{~cm}$. and $2 \mathrm{~cm}$. thick, thus having a volume of $1500 \mathrm{c}$. c., and is enclosed in a tight tin case, the lead-wires coming out through ebomite bushings. Nos. 1 to 4 of our condensers have a capacity of about 1.7 microfarad each; Nos. 5 to 10 , which were purchased about a year later, have a capacity of about $3 \cdot 2$ microfarads each. The condensers of the second lot are made of paper about $0038 \mathrm{~cm}$. thick, two sheets being placed together in each stratum. This we learned by dissecting some which we had broken down. It ought to be stated, however, that while the condensers are guaranteed by the makers to stand 500 volts alternating electromotive force, we have repeatedly subjected them to 1000 to 2000 volts, and in some cases for several hours at a time. Nos. 9 and 10 were upon one occasion maintained at 2250 (effective) volts, at a frequency of 130 , for over an hour, and showed no signs of being overtaxed. We have, however, broken several at voltages between 1000 and 2000. The paper of the first lot of condensers is thicker, but as we have never broken one of this lot we cannot state its thickness. From the fact that the capacity of each of these is about 60 per cent. as great as that of the others, while their volumes are substantially the same, we conclude that the thickness of the paper is about $\cdot 0048 \mathrm{~cm}$., supposing there are, as in the other, two sheets together in every stratum of the condensers.

In Table III. are given the results of seven separate experiments with Stanley condensers, which were made at intervals during the past three months. The frequency in every case except experiment 4 was estimated from the average frequency of the two dynamos of the Middletown lighting circuits. Experiments 1 and 3 were made when the faster dynamo was supplying the lines, the others were with the slower dynamo. All but No. 4, however, were with a relatively high frequency. No. 4 was made using a two-pole rotary transformer, supplying it with direct current, and running it at a speed of 1600 per minute. The percentage losses $(0)$ vary more among the different condensers at the same frequency than one would expect.

The percentage loss at the frequency 28 (Experiment 4) is .78 per cent., whereas at a frequency five times as great it is (Experiment 3) 1.00 per cent. At 120 it is, as would be expected, nearly as great as at 140 ; that is, it is $\cdot 96$ per cont. 
TABLE III.-Measurements of Energy

\begin{tabular}{|c|c|c|c|c|c|c|c|}
\hline $\begin{array}{c}(a) \\
\text { No. of } \\
\text { the } \\
\text { con- } \\
\text { denser. }\end{array}$ & Time. & $\begin{array}{c}(c) \\
\text { Period in } \\
\text { seconds for } \\
\text { each } \\
1000 \text { grams } \\
\text { of water. }\end{array}$ & $\begin{array}{c}(d) \\
\text { Average } \\
\text { tempera- } \\
\text { ture of the } \\
\text { ingoing } \\
\text { water. }\end{array}$ & $\begin{array}{c}(e) \\
\text { Average } \\
\text { tempera- } \\
\text { ture of the } \\
\text { outgoing } \\
\text { water. }\end{array}$ & $\begin{array}{c}(f) \\
\text { Increase } \\
\text { in tempe- } \\
\text { rature of } \\
\text { each } \\
1000 \text { grams } \\
\text { of water. } \\
(e)-(d) .\end{array}$ & $\begin{array}{c}(g) \\
\text { Totul heat } \\
\text { measured } \\
\text { (small } \\
\text { calories) } \\
(f) \times 1000\end{array}$ & $\begin{array}{c}(h) \\
\text { Small } \\
\text { calories } \\
\text { per second } \\
(g) \div(c)\end{array}$ \\
\hline (1) & $\begin{array}{ccc}\mathrm{h} & \mathrm{m} & \mathrm{s} \\
7 & 24 & 00 \\
7 & 59 & 50 \\
8 & 36 & 30 \\
9 & 13 & 30\end{array}$ & $\begin{array}{l}2150 \\
2200 \\
2220\end{array}$ & $\begin{array}{l}19 \cdot 71 \\
19 \cdot 81 \\
19 \cdot 82\end{array}$ & $\begin{array}{l}24 \cdot 12 \\
24 \cdot 11 \\
24 \cdot 20\end{array}$ & $\begin{array}{l}4 \cdot 41 \\
4 \cdot 30 \\
4: 38\end{array}$ & $\begin{array}{l}4410 \\
4300 \\
4380\end{array}$ & $\begin{array}{l}2 \cdot 057 \\
1.955 \\
1.973\end{array}$ \\
\hline $3 \& 4$ & $\begin{array}{rrr}12 & 33 & 25 \\
1 & 04 & 00 \\
1 & 36 & 00 \\
2 & 07 & 40 \\
2 & 40 & 00\end{array}$ & $\begin{array}{l}1835 \\
1920 \\
1900 \\
1940\end{array}$ & $\begin{array}{l}18.06 \\
18.04 \\
17.93 \\
17.98\end{array}$ & $\begin{array}{l}23 \cdot 30 \\
23 \cdot 43 \\
23 \cdot 40 \\
23 \cdot 47\end{array}$ & $\begin{array}{l}5 \cdot 24 \\
5 \cdot 39 \\
5 \cdot 47 \\
5 \cdot 49\end{array}$ & $\begin{array}{l}5240 \\
5390 \\
5470 \\
5490\end{array}$ & $\begin{array}{l}2 \cdot 856 \\
2 \cdot 808 \\
2 \cdot 879 \\
2 \cdot 830\end{array}$ \\
\hline $3 \& 4$ & $\begin{array}{lll}7 & 17 & 20 \\
7 & 46 & 20 \\
8 & 15 & 50 \\
8 & 45 & 23 \\
9 & 14 & 43\end{array}$ & $\begin{array}{l}1740 \\
1770 \\
1773 \\
1760\end{array}$ & $\begin{array}{l}16 \cdot 71 \\
16 \cdot 59 \\
16 \cdot 33 \\
16 \cdot 55\end{array}$ & $\begin{array}{l}22 \cdot 69 \\
22 \cdot 12 \\
22 \cdot 11 \\
22 \cdot 06\end{array}$ & $\begin{array}{l}\mathbf{5} \cdot 38 \\
5 \cdot 53 \\
\mathbf{5} \cdot 78 \\
5 \cdot 51\end{array}$ & $\begin{array}{l}\mathbf{5 3 8 0} \\
5530 \\
5780 \\
5510\end{array}$ & $\begin{array}{l}3 \cdot 092 \\
3 \cdot 124 \\
3 \cdot 260 \\
3 \cdot 131\end{array}$ \\
\hline $\begin{array}{l}(4) \\
3 \& 4\end{array}$ & $\begin{array}{rrr}12 & 21 & 12 \\
1 & 21 & 25 \\
2 & 37 & 30 \\
3 & 47 & 35\end{array}$ & $\begin{array}{l}3613^{*} \\
4565 \\
4205\end{array}$ & $\begin{array}{l}18 \cdot 45 \\
18 \cdot 67 \\
18 \cdot 80\end{array}$ & $\begin{array}{l}22 \cdot 46 \\
2247 \\
22 \cdot 46\end{array}$ & $\begin{array}{l}4 \cdot 01 \\
3 \cdot 80 \\
3 \cdot 66\end{array}$ & $\begin{array}{l}2807 * \\
3800 \\
3660\end{array}$ & $\begin{array}{l}0.777 \\
0.832 \\
0.870\end{array}$ \\
\hline$(\overline{\mathbf{5}})$ & 122420 & & & & & & \\
\hline 6. & $\begin{array}{rrr}12 & 55 & 10 \\
1 & 26 & 45 \\
1 & 59 & 30\end{array}$ & $\begin{array}{l}1850 \\
1895 \\
1965\end{array}$ & $\begin{array}{l}19 \cdot 44 \\
19 \cdot 55 \\
19 \cdot 48\end{array}$ & $\begin{array}{l}23 \cdot 25 \\
23 \cdot 20 \\
23 \cdot 20\end{array}$ & $\begin{array}{l}3 \cdot 78 \\
3 \cdot 65 \\
3 \cdot 72\end{array}$ & $\begin{array}{l}3786 \\
3650 \\
3720\end{array}$ & $\begin{array}{l}2.140 \\
1.926 \\
1.893\end{array}$ \\
\hline 10. & $\begin{array}{lll}6 & 05 & 08 \\
6 & 41 & 20 \\
6 & 54 & 30\end{array}$ & $\begin{array}{c}2182 \\
780\end{array}$ & $\begin{array}{l}1782 \\
18 \cdot 10\end{array}$ & $\begin{array}{l}22 \cdot 48 \\
22 \cdot 80\end{array}$ & $\begin{array}{l}466 \\
4 \cdot 70\end{array}$ & $\begin{array}{l}4660 \\
1739 \dagger\end{array}$ & $\begin{array}{l}2 \cdot 136 \\
2 \cdot 231\end{array}$ \\
\hline 10. & $\begin{array}{lll}2 & 17 & 55 \\
2 & 50 & 00 \\
3 & 21 & 30 \\
3 & 53 & 28 \\
4 & 25 & 00\end{array}$ & $\begin{array}{l}1925 \\
1890 \\
1918 \\
1952\end{array}$ & $\begin{array}{l}17 \cdot 96 \\
18 \cdot 05 \\
17 \cdot 98 \\
17 \cdot 92\end{array}$ & $\begin{array}{l}22 \cdot 35 \\
22 \cdot 39 \\
22 \cdot 44 \\
22 \cdot 44\end{array}$ & $\begin{array}{l}439 \\
4 \cdot 34 \\
4 \cdot 46 \\
4 \cdot 52\end{array}$ & $\begin{array}{l}4390 \\
4340 \\
4460 \\
4520\end{array}$ & $\begin{array}{l}2 \cdot 281 \\
2 \cdot 29 t \\
2 \cdot 325 \\
2 \cdot 315\end{array}$ \\
\hline
\end{tabular}

* The amount of water for this period was 700 grams. 
dissipated in Stanley Paraffin Condensers.

\begin{tabular}{|c|c|c|c|c|c|c|c|}
\hline (i) & (j) & (k) & (l) & $(m)$ & (n) & (o) & $(p)$ \\
\hline $\begin{array}{l}\text { Equivalent } \\
\text { watts } \\
=\text { average } \\
\text { calories } \times \mathrm{J} \\
(h) \times 4-1972 \text {. }\end{array}$ & $\begin{array}{c}\text { Fre- } \\
\text { quency. }\end{array}$ & $\begin{array}{c}\text { Electro- } \\
\text { motive } \\
\text { force } \\
\text { in volts. } \\
\mathrm{E} .\end{array}$ & $\begin{array}{c}\text { Current } \\
\text { in amperes. } \\
\text { I. }\end{array}$ & $\begin{array}{c}\text { Apparent } \\
\text { watts. } \\
\text { EI. }\end{array}$ & $\left\{\begin{array}{c}\cos \phi \\
(i) \div(m)\end{array}\right.$ & $\begin{array}{c}\text { Per cent. } \\
\text { loss }= \\
\pi \cot \phi \times 100 \\
(n) \times \pi \times 100 .\end{array}$ & $\left\{\begin{array}{c}\text { Eficieney }= \\
(1-\pi \cot \phi) \times 100 . \\
100-(o) .\end{array}\right.$ \\
\hline $8 \cdot 36$ & 140 & 1133 & 1.60 & 1813 & .0046 & 1.45 & $98 \cdot 55$ \\
\hline 11.93 & 120 & 1264 & $3 \cdot 1$ & 3918 & .0030 & .96 & 99.04 \\
\hline $13 \cdot 23$ & 140 & 1104 & 3.5 & 4179 & .0032 & 1.00 & 9900 \\
\hline 347 & 28 & 1659 & $\cdot 837$ & 1389 & .0025 & .78 & $99 \cdot 22$ \\
\hline $8 \cdot 34$ & 120 & 778 & $2 \cdot 34$ & 1822 & .0046 & 1.44 & $98 \cdot 56$ \\
\hline $9 \cdot 17$ & 120 & 1294 & $3 \cdot 0$ & 3882 & .0024 & $\cdot 74$ & $99 \cdot 26$ \\
\hline $9 \cdot 67$ & 120 & 1294 & $3 \cdot 0$ & 3882 & .0025 & 78 & $99 \cdot 22$ \\
\hline
\end{tabular}


(Experiment 2). Condenser No. 1, of the same lot, shows a loss of 1.45 per cent. at frequency 140 , which is 45 per cent. greater loss than Nos. 3 and 4 give. Of the second lot, No. 6 gives a large loss (Experiment 5), and other experiments which one of us has made by other methods show that all the other condensers of this lot have losses nearly the same as No. 6, excepting No. 10, which gives the smallest loss of any, $\cdot 74$ per cent. in one case and $\cdot 78$ per cent. in another (Experiments 6 and 7). Condenser No. 2 shows by other methods the same loss as 3 and 4. Hence we have the following singular results:-All of the first lot except one have a loss of 10 per cent. on high freguencies, and the exceptional condenser has a loss of 1.45 per cent. All the condensers of the second lot have substantially the same losses, about 1.5 per cent., and the exceptional one is scarcely more than one half as much as the others; the exseptional one of the first lot having the same loss as all but one of the second. There is no possibility of a confusion of numbers, for they were plainly stamped when purchased, and the capacities of the first and second lots are very different, as already stated. Our experiments do not indicate the reason for these large differences; but the existence of such differences is fully confirmed by measurements made by wholly independent methods, and which will shortly be published.

Wesleyan University,

Middletown, Conn., Sept. 1, 1898.

XV. On certain Properties of the Hypergeometrical Series, and on the fitting of such Series to Observation Polygons in the Theory of Chance. By Karl Pearson, F.R.S., University College, London*.

1. TN a paper entitled "Mathematical Contributions to the Theory of Evolution : Part II. Skew Variation in Homogeneous Material" + , I have pointed out that the following series, of which the skew-binomial is a special case $(n=\infty)$,

$$
\begin{aligned}
& \frac{p n(p n-1)(p n-2) \ldots(p n-r+1)}{n(n-1)(n-2) \ldots(n-r+1)} \times \\
& \left(1+r \frac{q n}{p n-r+1}+\frac{r(r-1)}{1.2} \frac{q n(q n-1)}{(p n-r+1)(p n-r+2)}\right. \\
& \left.\quad+\frac{r(r-1)(r-2)}{1.2 .3} \frac{q n(q n-1)(q n-2)}{(p n-r+1)(p n-r+2)(p n-r+3)}+\& c .\right) \\
& \quad \text { * Communicated by the Author. } \\
& \quad \text { Phil. Trans. vol. clxxx vi. p. 360 (1895). }
\end{aligned}
$$

